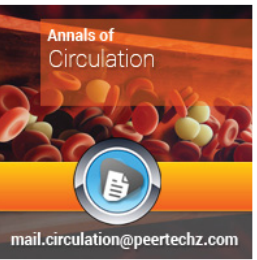

\title{
Annals of Circulation
}

Rohit Seth Loomba'*, Saurabh

Aggarwal $^{2}$, Navdeep Gupta' , Arun

Kanmanthareddy ${ }^{2}$, Imtiaz Ismail ${ }^{3}$,

Anushree Agarwal ${ }^{4}$, Karan Nijhawan ${ }^{5}$,

Gaurav Aggarwal ${ }^{6}$, Rohit Arora $^{3}$,

Marcelo SanMartin ${ }^{7}$ and Richard

Anderson $^{8}$

'Medical College of Wisconsin, Milwaukee, WI, USA ${ }^{2}$ Creighton University School of Medicine, Omaha, NE, USA

${ }^{3}$ Chicago Medical School, North Chicago, IL, USA

${ }^{4}$ University of California-San Francisco, San

Francisco, CA, USA

${ }^{5}$ Rush university Medicel Center, Chicago, IL, USA

${ }^{6}$ Armed Forces Medical College, Pune, India

${ }^{7}$ Unidad de Cardiología Intervencionista, Medtec,

Hospital Meixoeiro, Vigo, Spain

\&University Hospital of Wales, Cardiff, Wales, UK

Dates: Received: 23 March, 2017; Accepted: 28

March, 2017; Published: 30 March, 2017

*Corresponding author: Rohit Seth Loomba, Medical College of Wisconsin, Milwaukee, WI, USA, E-mail:

loomba.rohit@gmail.com

https://www.peertechz.com
Research Article

\section{Comparison of Transradial and}

Transfemoral Access for Coronary

Bypass Graft Angiography

\section{Abstract}

Introduction: Transradial access has been shown to be safe and effective in the setting of percutaneous coronary intervention $(\mathrm{PCl})$ and even being beneficial in regards to vascular complications and perceived quality of life after the intervention. However, data is limited in patients having previously undergone coronary artery bypass grafting $(C A B G)$ where procedural complexity can be increased.

Methods: Studies comparing transradial and transfemoral access for $\mathrm{PCl}$ in patients having undergone CABG were identified. Data for similar endpoints was extracted for subsequent meta-analysis. Bias and heterogeneity were also assessed.

Results: There was no significant difference in procedure success (OR $0.87,95 \% \mathrm{Cl} 0.43$ to 1.73 , $\mathrm{p}=0.68$ ), procedure time (MD 231.98 seconds, $95 \% \mathrm{Cl}-84.39$ to $548.36, \mathrm{p}=0.15$ ), fluoroscopy time (MD 51.75 seconds, $95 \% \mathrm{Cl}-66.83$ to $170.34, \mathrm{p}=0.39$ ), contrast volume (MD 1.67 milliliter, $95 \% \mathrm{Cl}-22.16$ to $25.49, \mathrm{p}=0.89$ ) and in-hospital mortality (OR $0.50,95 \% \mathrm{Cl} 0.13$ to $1.92, \mathrm{p}=0.31$ ) between those in the transradial and transfemoral access groups. Transradial access was associated with fewer vascular complications (OR $0.33,95 \% \mathrm{Cl} 0.16$ to $0.72, \mathrm{p}=0.005$ ).

Conclusions: Transradial access for PCI in patients with prior CABG is safe, with fewer vascular complications, and offers an effective and potentially favorable alternative to transfemoral access.

Condensed abstract: Transradial access has been demonstrated to offer benefits in comparison to transfemoral access for percutaneous coronary intervention (PCl). This advantage has not been fully elucidated for $\mathrm{PCl}$ of coronary artery bypass grafts (CABG). A meta-analysis was conducted to study the two access options and found that transradial access for PCl of CABG grafts is safe and may in fact be associated with fewer vascular complications.

\section{Introduction}

Transradial access has been associated with a decrease in vascular complications, bleeding complications, inhospital mortality, and time to ambulation when compared to transfemoral access in the setting of percutaneous coronary intervention (PCI). These benefits, though, may be at the expense of longer procedural times and increased radiation exposure [1-9]. Studies that have established this, however, have often excluded patients having previously undergone coronary artery bypass grafting (CABG) and thus data in this population is not readily available. This population is of particular interest as PCI in them is generally more difficult, requiring increased number of catheter exchanges, contrast volume, and radiation exposure.

There have been a few observational studies and a single randomized trial conducted to help evaluate transradial access for angiography in those having previously undergone CABG [9-15]. The aim of this study was to provide a pooled analysis of all currently available studies in order to better characterize the utility of transradial access for PCI in those with a history of CABG.

\section{Methods}

A systematic review of the literature was performed to identify manuscripts describing comparisons between radial and femoral access for coronary artery bypass graft angiography. This was a newly conducted review and no previous review protocol has been established for it. The transradial and transfemoral access for CABG angiography were compared for the following outcomes: procedural success, procedure time, fluoroscopy time, contrast volume, in-hospital mortality, and 
vascular complications. Total procedure time was defined as the time between administration of local anesthesia for vascular access until all catheters were removed. Procedure time was analyzed in seconds as was fluoroscopy time. Contrast volume was presented in milliliters.

\section{Manuscript search and identification strategy}

Manuscripts were identified using electronic databases including PubMed, EMBASE, and Ovid which were queried using the following search terms in various combinations: "transradial", "transfemoral", "radial", "femoral", "coronary artery bypass graft" or "angiography". No specific restriction on year of publication was used. Studies in language other than English were excluded. Resulting studies were then screened by title and abstract with manuscripts describing radial and femoral access in the setting of CABG angiography being retrieved in their entirety. References of these were hand searched for additional relevant manuscripts. No direct contact with manuscript authors was required to obtain full text manuscripts.

These full text manuscripts were then reviewed by two of the authors and assessed for quality. Any disparities in scoring of manuscripts were then independently reviewed by another author. The Cochrane Handbook for Systematic Review of Interventions was used for quality evaluation. Published manuscripts available in full text were included in this review if they presented data comparing transradial and transfemoral access for CABG angiography with respect to the outcomes listed above. Studies were included in this analysis if they included at least one of the outcomes identified above.

\section{Data extraction}

Data regarding baseline patient characteristics and identified outcomes were extracted from the manuscripts identified for inclusion. Trial level data was extracted independently with use of a data collection form by two authors. The data extraction was then independently reviewed by another author to ensure integrity of the resulting data. If no information was available about particular outcomes, this was designated separately. Authors of included studies were not contacted for additional data.

\section{Bias analysis}

Bias was assessed using the physiotherapy evidence database (PEDro) scale. Specifically, patient eligibility, randomization and concealment of allocation, blinding completeness of outcome data, and statistical integrity were assessed using this scale.

\section{Data analysis}

Numeric data are presented as means with standard deviations or medians with ranges. Categorical data are presented as frequencies with absolute numbers as well as percentages. Results are presented as pooled odds ratios (OR) with $95 \%$ confidence intervals (CI) or as standard mean difference (MD) where appropriate. Heterogeneity between studies was identified using chi-square and $\mathrm{I}^{2}$ tests.
For outcomes with no significant heterogeneity present, a fixed effects model was used. A random effects model was used if either the $\mathrm{p}$-value was significant or the $\mathrm{I}^{2}$ statistics was greater than $50 \%$. P-values of $\leq 0.05$ were considered statistically significant. This analysis was done using SPSS statistical software, version 20.0 (Chicago, IL). Meta-analysis and forest plot creation were done using RevMan 5.0 (Cochrane Collaboration, Oxford, UK).

For some endpoints the analysis was run twice, including and excluding the only randomized control trial to gauge the effect of this study on the outcome.

\section{Results}

Initial search as outlined above yielded 41 manuscripts. After reviewing the title and abstract, full text manuscripts were obtained for 19 of these studies. Of these 19 studies, 7 studies were identified for inclusion in the analysis. Study methodology is depicted in figure 1. There were a total of 1,370 patients across these studies with 583 undergone CABG angiography via transradial access and 787 undergone CABG angiography via transfemoral access. Six of these studies were observational and one was a randomized control trial (9-15). Study quality and bias analysis are depicted in tables 1,2 .

\section{Procedural success}

Five studies were analyzed for procedural success, yielding a total of 583 patients in the transradial group and 787 patients in the transfemoral group. There was no significant difference with respect to procedural success between the two groups (OR $0.87,95 \%$ CI 0.43 to $1.73, \mathrm{p}=0.68$ ) (Figure 2). No significant heterogeneity present as demonstrated by a chi-squared value of $2.84(\mathrm{p}=0.59)$ and an $\mathrm{I}^{2}$ of $0 \%$. When the analysis was repeated without the randomized control trial there were similar findings.

\section{Procedure time}

Data from a total of six studies was pooled for analysis of procedural time with a total of 486 patients in the transradial group and 579 patients in the transfemoral group. There was no significant difference with respect to procedure time between

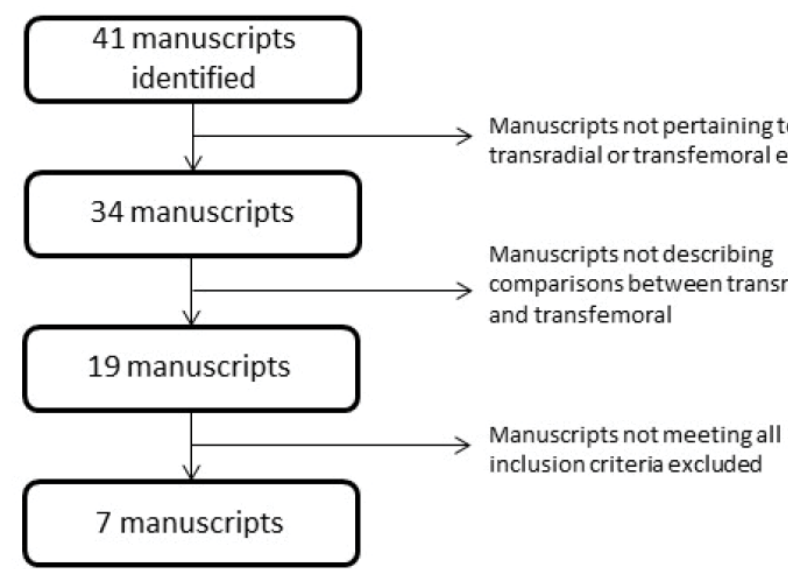

Figure 1: Study selection methodology for meta-analysis comparing transradial and transfemoral access for coronary artery bypass graft angiography. 
the two groups (MD 231.98 seconds, $95 \% \mathrm{CI}-84.39$ to 548.36 , p $=0.15$ ) (Figure 3). A random effects model was utilized as there was significant heterogeneity present as demonstrated by a chi-squared value of $25.40(\mathrm{p}<0.001)$ and an $\mathrm{I}^{2}$ of $80 \%$. When the analysis was repeated without the randomized control trial there were similar findings.

Table 1: Quality of studies assessing transradial versus transfemoral access for saphenous vein graft angiography.

\begin{tabular}{|c|c|c|c|c|}
\hline Study & Selection & Comparability & Outcome & Overall \\
\hline Bundhoo et al & 3 & 2 & 3 & 8 \\
\hline Burzotta et al & 4 & 2 & 3 & 9 \\
\hline Han et al & 3 & 2 & 3 & 8 \\
\hline Michael et al & 4 & 2 & 3 & 9 \\
\hline Rathore et al & 4 & 2 & 3 & 9 \\
\hline Sanmartin et al & 4 & 2 & 3 & 9 \\
\hline Ziakas et al & 3 & 2 & 3 & 8 \\
\hline
\end{tabular}

Table 2: Analysis of bias in studies assessing transradial versus transfemoral access for saphenous vein graft angiography.

\begin{tabular}{|c|c|c|c|c|c|c|}
\hline $\begin{array}{c}\text { Study } \\
\text { (country) }\end{array}$ & $\begin{array}{c}\text { Random } \\
\text { Sequence } \\
\text { Generation }\end{array}$ & $\begin{array}{c}\text { Allocation } \\
\text { Concealment }\end{array}$ & Blinding & $\begin{array}{c}\text { Incomplete } \\
\text { Outcome } \\
\text { Data }\end{array}$ & $\begin{array}{c}\text { Free of } \\
\text { Selective } \\
\text { Outcome } \\
\text { Reporting }\end{array}$ & $\begin{array}{c}\text { Other } \\
\text { Bias }\end{array}$ \\
\hline $\begin{array}{c}\text { Bundhoo et } \\
\text { al (United } \\
\text { Kingdom) }\end{array}$ & High & Low & High & Low & Low & Low \\
\hline $\begin{array}{c}\text { Burzotta et al } \\
\text { (Italy) }\end{array}$ & Low & Low & Low & Low & Low & Low \\
\hline $\begin{array}{c}\text { Han et al } \\
\text { (China) }\end{array}$ & High & Low & High & Low & Low & Low \\
\hline $\begin{array}{c}\text { Michael et al } \\
\text { (United } \\
\text { States) }\end{array}$ & Low & Low & Low & Low & Low & Low \\
\hline $\begin{array}{c}\text { Rathore et al } \\
\text { (United } \\
\text { Kingdom) }\end{array}$ & High & Low & High & Low & Low & Low \\
\hline $\begin{array}{c}\text { Sanmartin } \\
\text { et al } \\
\text { (Spain) }\end{array}$ & Hlgh & Low & High & Low & Low & Low \\
\hline $\begin{array}{c}\text { Ziakas et al } \\
\text { (Canada) }\end{array}$ & High & Low & High & Low & Low & Low \\
\hline
\end{tabular}

\section{Fluoroscopy time}

Five studies with a total of 495 patients in the transradial group and 691 patients in the transfemoral group were pooled for analysis of fluoroscopy time. There was no significant difference with respect to fluoroscopy time between the two groups (MD 51.75 seconds, 95\% CI -66.83 to $170.34, \mathrm{p}=0.39$ ) (Figure 4). Significant heterogeneity was present and so a random effects model was utilized (chi-squared value of 20.65, $\mathrm{p}<0.001, \mathrm{I}^{2}$ of $81 \%$ ). When the analysis was repeated without the randomized control trial, there were similar findings.

\section{Contrast volume}

Data from a total of four studies was pooled for analysis of contrast volume with a total of 398 patients in the transradial group and 483 patients in the transfemoral group. There was no significant difference with respect to contrast volume between the two groups (MD 1.67 milliliter, 95\% CI -22.16 to $25.49, \mathrm{p}=$ 0.89) (Figure 5). A random effects model was utilized as there was significant heterogeneity present as demonstrated by a chi-squared value of $12.82(\mathrm{p}=0.005)$ and an $\mathrm{I}^{2}$ of $77 \%$. When the analysis was repeated without the randomized control trial there were different findings. Without the randomized control there were a total of 4 studies with 334 patients in the transradial group and 419 patients in the transfemoral group. There was a significant difference in contrast volume utilized with less contrast being utilized in those in the transradial group (MD -12.52 milliliters, 95\% CI -24.47 to $-0.56, \mathrm{p}=0.04$ ) (Figure 6). A fixed effects model was utilized as there was no significant heterogeneity present as demonstrated by a chisquared value of $068(\mathrm{p}=0.71)$ and an $\mathrm{I}^{2}$ of $0 \%$.

\section{In-hospital mortality}

Four studies were pooled for analysis of in-hospital mortality with a total of 348 patients in the transradial group and 530 patients in the transfemoral group. No significant difference was noted with respect to in-hospital mortality between the two groups (OR $0.50,95 \%$ CI 0.13 to $1.92, \mathrm{p}=0.31$ ) (Figure 7). There was no significant heterogeneity present as demonstrated by a chi-squared value of $0.16(\mathrm{p}=0.98)$ and an $\mathrm{I}^{2}$ of $0 \%$.

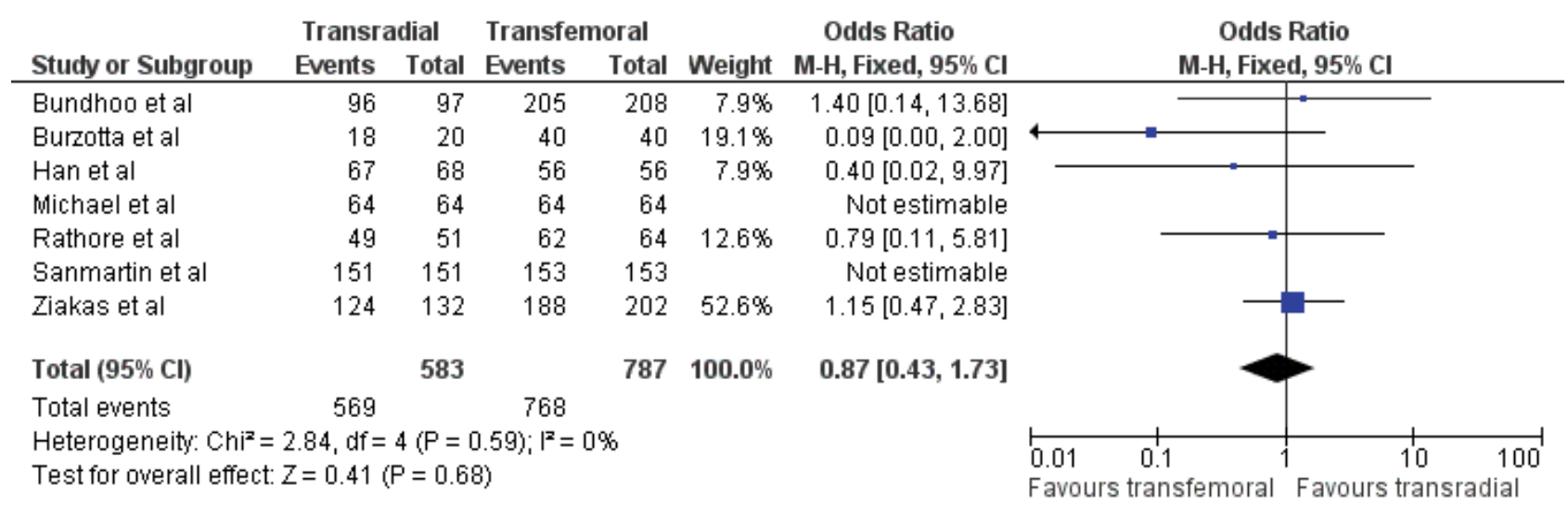

Figure 2: Results of procedural success in transradial versus transfemoral access for coronary artery bypass graft angiography 


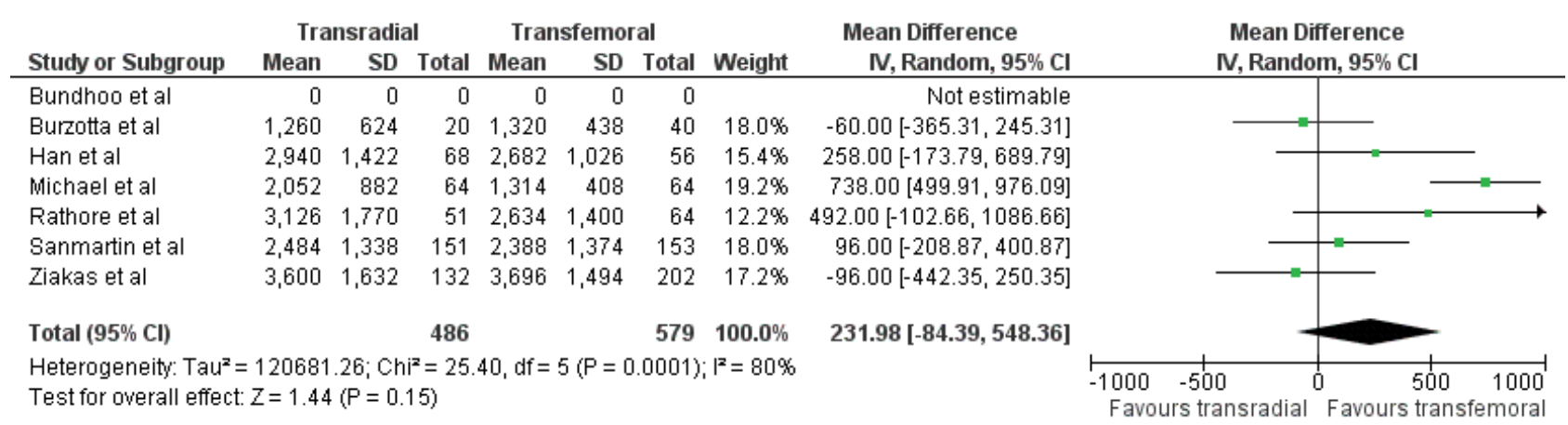

Figure 3: Results of procedural time in transradial versus transfemoral access for coronary artery bypass graft angiography.

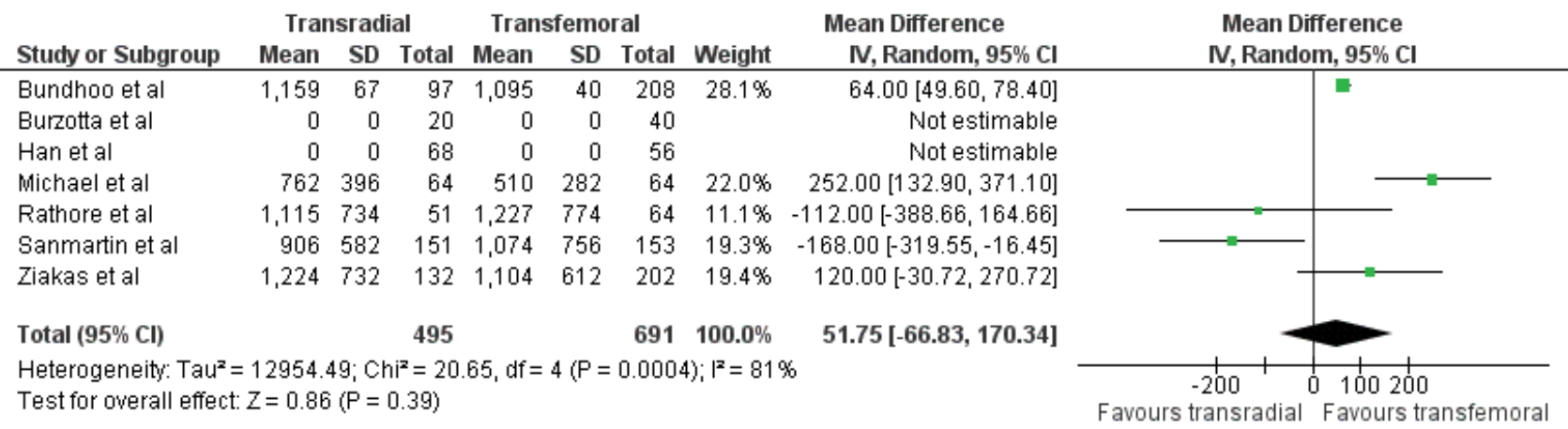

Figure 4: Results of fluoroscopy time in transradial versus transfemoral access for coronary artery bypass graft angiography.

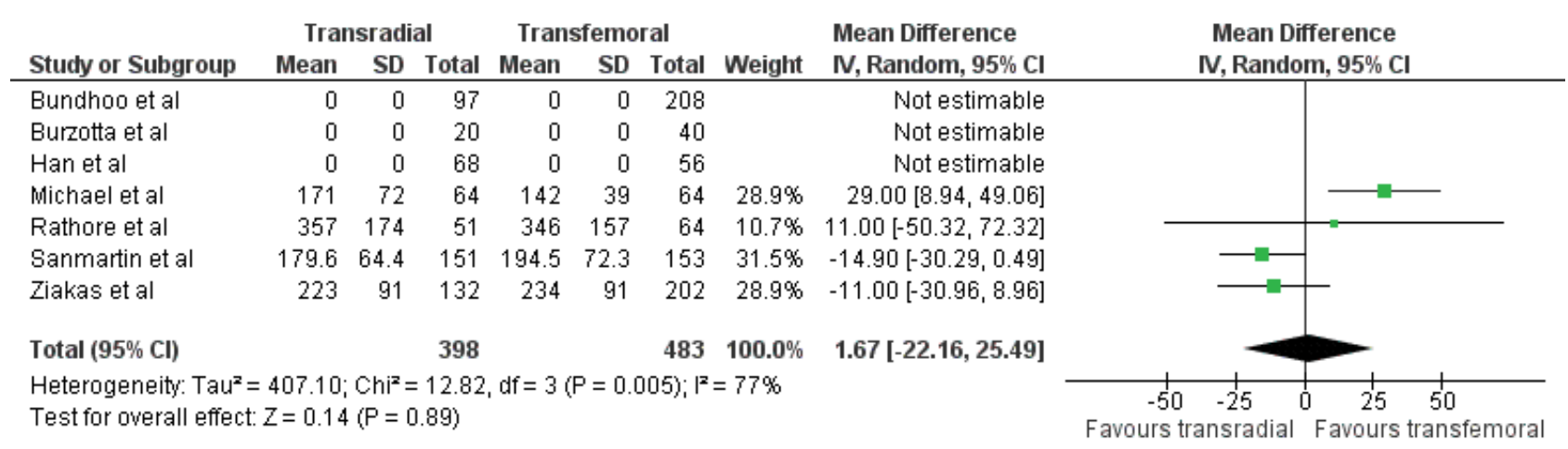

Figure 5: Results of contrast volume in transradial versus transfemoral access for coronary artery bypass graft angiography.

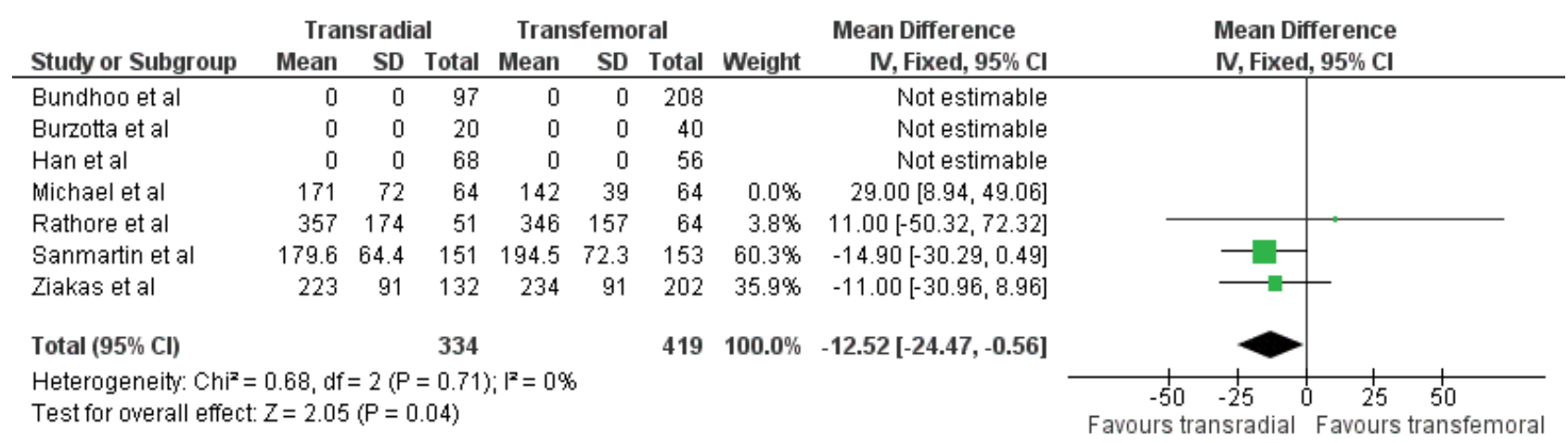




\section{Vascular complications}

Data from seven studies was pooled for analysis of vascular complications with a total of 582 patients in the transradial group and 786 patients in the transfemoral group. There was a significant difference with respect to vascular complications between the two groups with fewer vascular complications in the transradial group (OR $0.33,95 \%$ CI 0.16 to $0.72, \mathrm{p}=0.005$ ) (Figure 8). A fixed effects model was utilized as there was no significant heterogeneity present as demonstrated by a chisquared value of $4.15(=0.66)$ and an $\mathrm{I}^{2}$ of $0 \%$. This finding did not change when the analysis was repeated without the randomized control trial.

\section{Crossover rates and side of radial access}

Crossover rates were not formally pooled. This data was available for 6 studies and range from $1 \%$ to $17 \%$ for transradial to transfemoral and ranged from 0 to $4 \%$ for transfemoral to transradial. The mean crossover from transradial to transfemoral was approximately $3 \%$.

Only 4 studies commented on the side from which transradial access was obtained. In 2 of these studies all transradial access was obtained on the left, in 1 of these studies left sided access was obtained in $89 \%$, and in the remaining study the side of access was operator dependent but specific numbers were not provided.

\section{Discussion}

This pooled analysis demonstrates that transradial access appears to be a safe and effective option for PCI in those previously having undergone CABG. When compared to transfemoral access, transradial access performed equally well with respect to procedural success, procedure time, fluoroscopy time, and in-hospital mortality. There may be an advantage associated with transradial access with respect to contrast volume and vascular complications. These are important findings in cases that can be technically more challenging than those without previous CABG. Thus, the radial approach demonstrates extended clinical utility in to this complex patient cohort. Another point of note is that findings did not change significantly if only randomized trials or observational studies were analayzed separately.

It should be noted that operators in the included studies were all well experienced with transradial access. Thus these studies present results from ideal environments and there may be a learning curve for operators less experienced with transradial access. The crossover rate was low in all included studies, and was predominantly due to radial artery spasm.

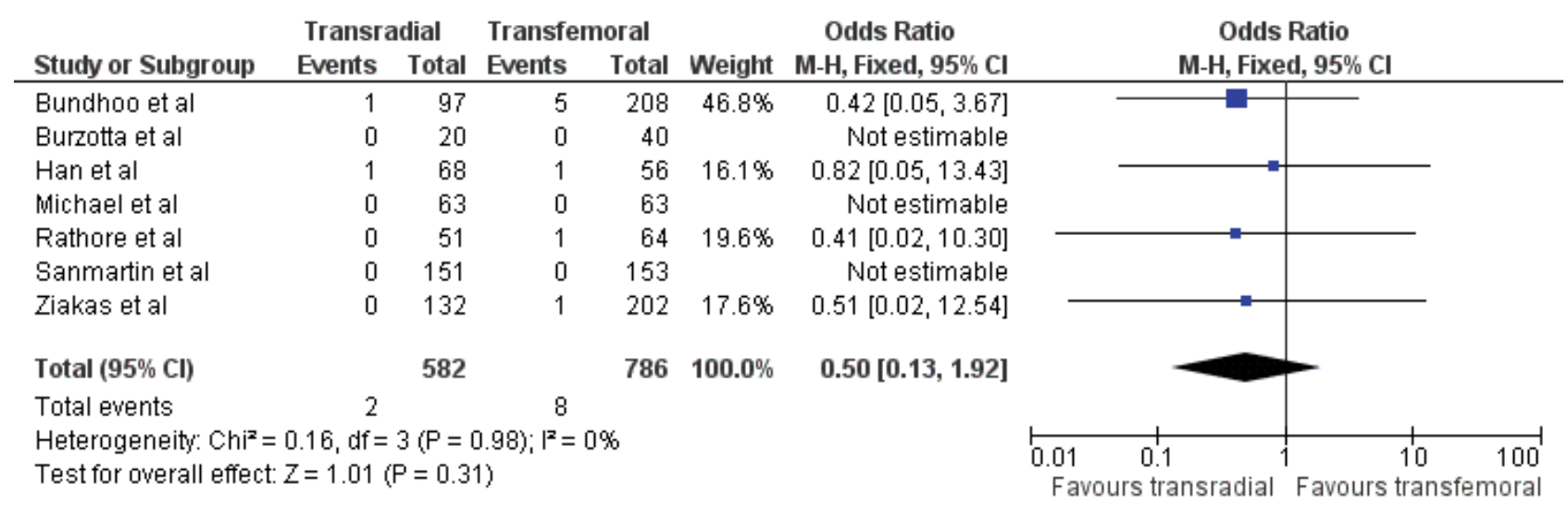

Figure 7: Results of in-hospital mortality in transradial versus transfemoral access for coronary artery bypass graft angiography

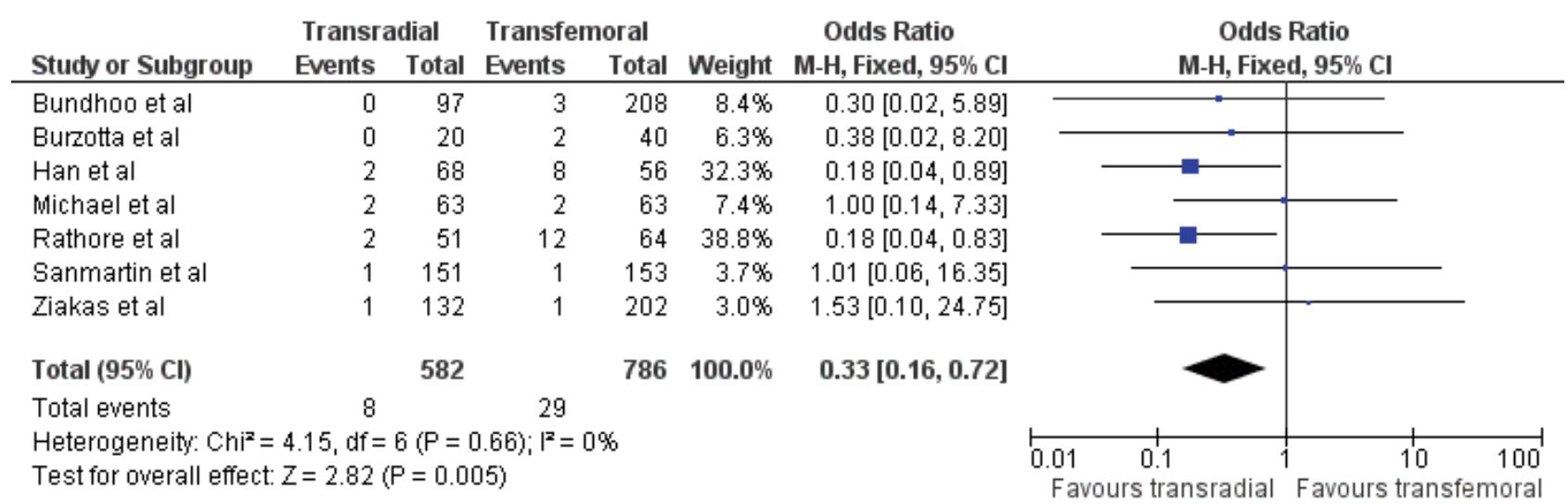

Figure 8: Results of vascular complications in transradial versus transfemoral access for coronary artery bypass graft angiography 
Other reasons for crossover include difficulty puncturing the radial artery, difficulty passing a wire or sheath, and inability to access the target vessel.

Outside of patients having undergone previous CABG, studies have demonstrated lower rates of access site complications, high procedural success rates, and similar procedure time with transradial access when compared to transfemoral route for PCI [16]. A large meta-analysis of approximately 3.000 patients demonstrated the safety of the transradial approach across all available studies [3]. Thus, when compared to results of this current analysis, it appears that these advantages do in fact extend to PCI in patients with a history of CABG, a patient population underrepresented in a majority of studies comparing transradial and transfemoral access. It is interesting to note that some previous studies have demonstrated higher fluoroscopy times and radiation exposure with transradial access compared to transfemoral access. Even within the current analysis there were three studies that demonstrated this, although in the pooled analysis there was no statistically significant difference $[9,10,13]$.

The limitations of this analysis include the fact that all but one of the studies included are retrospective observational studies. With limited data regarding varying access strategies in this particular population, however, it seemed prudent to analyze all these studies. To determine the effect of the randomized control trial on the overall analysis, a second analysis was conducted without this study included for selected endpoints. For all but one of these endpoints, there was no change in the result. Not enough data was available from the selected studies to run analysis for major adverse cardiovascular events or for specific radiation exposure in air kerma. There was also significant heterogeneity among included studies for some endpoints. Random effects model was used to help adjust for this. Bias was analyzed and there was limited bias within the studies. Publication bias was not assessed quantitatively or qualitatively due to small number of studies.

\section{Conclusion}

Transradial access appears to be equally safe when compared to transfemoral access for PCI in patients previously having undergone $\mathrm{CABG}$, and may be associated with fewer vascular complications and a decrease in contrast volume.

\section{References}

1. Rao SV, Ou FS, Wang TY, Roe MT, Brindis R, et al. (2008) Trends in the prevalence and outcomes of radial and femoral approaches to percutaneous coronary intervention: a report from the National Cardiovascular Data Registry. JACC Cardiovasc Interv 1: 379-386. Link: https://goo.gl/iKvOsE

2. Hamon M, Mehta S, Steg PG, Faxon D, Kerkar P, et al. (2011) Impact of transradial and transfemoral coronary interventions on bleeding and net adverse clinical events in acute coronary syndromes. Eurolntervention 7: 9197. Link: https://goo.gl/A6aJNo

3. Agostoni P, Biondi-Zoccai GG, de Benedictis ML, Rigattieri S, Turri M, et al. (2004) Radial versus femoral approach for percutaneous coronary diagnostic and interventional procedures; Systematic overview and meta-analysis of randomized trials. J Am Coll Cardiol 44: 349-356. Link: https://goo.gl/KAGGGB
4. Jolly SS, Yusuf S, Cairns J, Niemela K, Xavier D, et al. (2011) Radial versus femoral access for coronary angiography and intervention in patients with acute coronary syndromes (RIVAL): a randomised, parallel group, multicentre trial. Lancet 377: 1409-1420. Link: https://goo.gl/yHngVY

5. Valgimigli M, Saia F, Guastaroba $P$, Menozzi A, Magnavacchi $P$, et al. (2012) Transradial versus transfemoral intervention for acute myocardial infarction a propensity score-adjusted and -matched analysis from the REAL (REgistro regionale AngiopLastiche dell'Emilia-Romagna) multicenter registry. JACC Cardiovascular interventions 5: 23-35. Link: https://goo.gl/MgER9t

6. Romagnoli E, Biondi-Zoccai G, Sciahbasi A, Politi L, Rigattieri S, et al. (2012) Radial versus femoral randomized investigation in ST-segment elevation acute coronary syndrome: the RIFLE-STEACS (Radial Versus Femoral Randomized Investigation in ST-Elevation Acute Coronary Syndrome) study. J Am Coll Cardiol 60: 2481-2489. Link: https://goo.gl/976ZvH

7. Chodor P, Krupa H, Kurek T, Sokal A, Swierad M, et al. (2009) RADlal versus femoral approach for percutaneous coronary interventions in patients with Acute Myocardial Infarction (RADIAMI): A prospective, randomized, singlecenter clinical trial. Cardiol J 16: 332-340. Link: https://goo.gl/Lds5Pt

8. Cooper CJ, El-Shiekh RA, Cohen DJ, Blaesing L, Burket MW, et al. (1999) Effect of transradial access on quality of life and cost of cardiac catheterization: A randomized comparison. Am Heart J 138: 430-436. Link: https://goo.gl/ijGzbW

9. Ziakas A, Klinke P, Mildenberger R, Fretz E, Williams M, et al. (2005) A comparison of the radial and the femoral approach in vein graft PCI. A retrospective study. International journal of cardiovascular interventions 7 93-96. Link: https://goo.gl/4m55m7

10. Bundhoo SS, Earp E, Ivanauskiene T, Kunadian V, Freeman P, et al. (2012) Saphenous vein graft percutaneous coronary intervention via radial artery access: safe and effective with reduced hospital length of stay. Am Heart J 164: 468-472. Link: https://goo.gl/3NjzUd

11. Burzotta F, Trani C, Todaro D, Romagnoli E, Niccoli G, et al. (2008) Comparison of the transradial and transfemoral approaches for coronary angiographic evaluation in patients with internal mammary artery grafts. J Cardiovasc Med 9: 263-266. Link: https://goo.gl/xWaFmC

12. Han H, Zhou Y, Ma H, Liu Y, Shi D, et al. (2012) Safety and feasibility of transradial approach for coronary bypass graft angiography and intervention. Angiology 63: 103-108. Link: https://goo.gl/KS9oGY

13. Michael TT, Alomar M, Papayannis A, Mogabgab O, Patel VG, et al. (2013) A randomized comparison of the transradial and transfemoral approaches for coronary artery bypass graft angiography and intervention: the RADIALCABG Trial (RADIAL Versus Femoral Access for Coronary Artery Bypass Graft Angiography and Intervention). JACC Cardiovasc Interv 6: 1138-1144. Link: https://goo.gl/bW3B50

14. Rathore S, Roberts E, Hakeem AR, Pauriah M, Beaumont A, et al. (2009). The feasibility of percutaneous transradial coronary intervention for saphenous vein graft lesions and comparison with transfemoral route. Journal of interventional cardiology 22: 336-340. Link: https://goo.gl/g7h4nd

15. Sanmartin M, Cuevas D, Moxica J, Valdes M, Esparza J, et al. (2006) Transradial cardiac catheterization in patients with coronary bypass grafts: feasibility analysis and comparison with transfemoral approach. Catheterization and cardiovascular interventions : official journal of the Society for Cardiac Angiography \& Interventions 67: 580-584. Link: https://goo.gl/n2TZOP

16. Kiemeneij F, Laarman GJ, Slagboom T, van der Wieken R. (1997) Outpatient coronary stent implantation. Journal of the American College of Cardiology 29: 323-327. Link: https://goo.gl/a4Oge0

Copyright: () 2017 Loomba RS, et al. This is an open-access article distributed under the terms of the Creative Commons Attribution License, which permits unrestricted use, distribution, and reproduction in any medium, provided the original author and source are credited. 